\title{
The impact of implementing continuous improvement upon stress within a Lean
}

\section{production framework}

\section{Summary}

The purpose of this research is to understand the impact of implementing continuous improvement upon the occupational stress of employees within the framework of Lean management. The outcomes of empirical research mobilizing a mixed methodology proves that continuous improvement can help attenuate stress levels, whilst achieving or surpassing economic performance objectives, if its implementation means an effective and satisfactory participation by both employees as well as by management. Conversely, when there is no continuous improvement or it is ill-suited, Lean results in greater stress. These findings confirm the interest in furthering insight into Lean management by moving from a global approach to an approach integrating the effects of its various pillars, especially continuous improvement.

Key words: Lean production, continuous improvement, Kaizen, occupational health, stress

\section{Introduction}

Although the economic efficiency of Lean production (LP) is not at issue (Fullerton, 2014), it is a different matter as regards to its impact on health. Arezes et al. (2015) point to the complexity of the relationship between LP and workers' health. Despite the wealth of literature with its particular focus on safety (Longoni et al., 2013) and musculoskeletal disorders (Koukoulaki, 2014), stress defined by Cox (2000) as the nervousness / anxiety associated with work affecting the employee emotionally and physically on their health, remains a less common area of study (Conti et al., 2006). In addition, Longoni et al. (2013) emphasize that a binary reading of LP is a recipe for disregarding the diversity in its usage. 
The authors encourage the scientific community to consider LP more precisely by refocusing the analysis on the impact of the diversity of applications of the founding principles (Netland, 2016; Shah and Ward, 2003).

It therefore seems of prime importance not only to endow oneself with a greater wealth of study on the link between LP and stress but also to integrate the diversity of practices without considering LP as a homogeneous practice. The purpose of this article is to address the following research question: what is the impact of the implementation of continuous improvement (CI) upon the occupational stress of employees within the framework of Lean management? In doing so, without refuting the relevance of the work on safety or other physical dimensions of health, this research considers them as an additional source of food for thought. Lean is defined here as a context for which we ensure that a minimum threshold of completeness is reached to focus on what is often a weak link: continuous improvement.

There are two reasons for choosing CI. Firstly, after many field studies, Imai (1986) considers that western transpositions of Lean and Toyotism most often steers clear of CI (Kaizen) in favor of more immediate approaches. Other more contemporary authors like Tortorella et al. (2015), also make CI the cornerstone of any Lean approach. Secondly, CI defined as "a particular bundle of routines which can help an organization improve what it currently does" (Bessant and Francis, 1999) and known as 'Kaizen' in Japanese, appears to be the most difficult to implement but also has a potentially positive impact on health (Conti et al., 2006).

We will rely on a mixed methodology according to a complementarity design (Greene et al., 1989). By so doing we will obtain different but complementary data to better ascertain the research issue (Morse, 1991). We will perceive different facets of a phenomenon in order to acquire a fuller understanding. In accordance with the works of Saurin and Ferreira (2009), 
our unit of analysis is the workshop, as this level appears as the most relevant for appraising the implementation of LP (Knol et al., 2018). Our empirical data consists of 16 workshops located across 6 companies.

Our research makes a threefold contribution to the literature. Firstly, by showing that a controlled Kaizen allows LP to produce a moderating effect on employee stress, we reinforce recent work on health and safety (Longoni et al., 2013) or musculoskeletal disorders (Koukoulaki, 2014) which underlines the moderating effect of socio-technical linkage practices. Secondly, this research goes beyond the distinction made by Pettersen (2009) between a Lean tool and a Lean system by demonstrating the existence of pseudo-systemic Lean that is more destructive for employees than the other two forms. This finding bears witness to the potential better understanding of LP implementation and helps explain why it can be perceived that LP is a health hazard for employees. Thirdly, this research confirms the significance of managerial involvement and the active participation of employees as key elements in a successful CI implementation. Moreover, this research shows that it is not just a matter of holding regular meetings, but that meetings must be organized with a rapid response towards the decisions taken and towards the communication between the operators and their hierarchy. More extensively and methodologically speaking, the research is based on the experience of those who live it and not only on those who manage it. This research places people at the center of LP whereas previously they had been sidelined due to a focus on optimizing the process performance (Shoaf et al., 2004).

The article is structured in three parts. After a review of the literature on LP, its effects on stress and the role played by Kaizen, we describe our results obtained from the study of the 16 
workshops. We conclude by comparing our results with those put forward by the scientific community as well as underlining their managerial implications.

\section{The link between LP and well-being of workers}

Following Imai (1986), who makes continuous improvement a central, distinctive, and often neglected element of Western LP transpositions, we choose among the many definitions of Lean management (Arezes et al., 2015, Koukoulaki, 2014) the one that bestows pride of place to CI. Continuous improvement is, in this setting, a core factor in the distinction between Lean tool and systemic Lean (Pettersen, 2009), where operators are thinkers and not only factors of production (Alves et al., 2012). Standing on several pillars, which constitute sources of heterogeneity within its application, LP is defined as "an approach that includes principles and management practices that aim to reduce waste and improve operational efficiency throughout the entire value stream in continuous improvement endless journey" (Tortorella et al., 2015).

Analyzing the literature on the link between LP and health between 1990 and 2013, Koukoulaki (2014) describes the developments towards understanding it. A first period describes Lean as harmful by nature to the health of the employee. For instance, Bruno and Jordan (2002) question the negative nature of LP for health. Lewchuk and Robertson (1999) point out that it is the workers working towards LP who have the highest level of stress in comparison with other modes of work organization such as Ford mass production. A second period describes an ambivalent impact of LP on health. Saurin and Feirrera (2009) identify 52 items and conclude that $52 \%$ have a negative impact on health, while $48 \%$ point towards positive effects. The authors emphasize, however, that most items produce ambivalent 
outcomes or positive and negative effects, such as what Hasle et al. (2012) put forward in their literature review on the effects of Lean management on the well-being of employees.

More recently, by integrating the heterogeneity of LP, research has forged links between the pillars of Lean and the specific consequences for health. Conti et al. (2006) identify eleven practices potentially hazardous to the occupational stress of employees. Koukoulaki (2014) suggests that practices linked to ‘just in time’ or Total Quality Management, are conducive to employees suffering stress. Longoni et al. (2013) support these results in part by showing that just-in-time practices alone are negative for health. However, the authors point out that certain principles can produce a positive effect. Based on the work of Forza (1996), Conti et al. (2006) demonstrate that CI can allow employees to improve their control over their work and reduce their stress. In general, the participation of employees and their autonomy appear as elements triggering positive health dynamics (Monroe et al., 2012). Longoni et al. (2013) state that the preventive factors (maintenance and human resources) have a decisive impact on health such as CI for work accidents. The authors insist that there is a risk of a harmful LP if management practices do not go hand in hand with the development of power sharing. When concluding his literature review on the Lean health link, Koukoulaki (2014) broadens the debate by registering the link between in-company technical and social systems. He stresses that research must better grasp how the social system of the company can implement practices that counterbalance the effects structurally jeopardizing the health of essentially technical LP practices such as Just in Time.

Confirming the findings of Koukoulaki (2014), Arezes et al. (2015) point out that health problems stem from the misapplication of Lean principles. The implementation of Lean appears to be the defining criterion (Westgaard and Winkel, 2011). These findings are in line 
with several other earlier works, such as of Jackson and Martin (1996), which emphasize that it is possible to apply LP without causing stress if there is due reflection on the conditions for its application. Moreover, Bamber et al. (2014) stress that lean management should be understood as the linkage of different practices that may produce contradictory effects on the employee's health as their application may be heterogeneous. We will subsequently focus on the impact of the CI across this heterogeneity.

\section{What role for continuous improvement in the occupational stress / LP relationship?}

There exist miscellaneous applications of Kaizen that rarely achieve the expected levels of success. In an early study, Choi (1998) conducted longitudinal monitoring of the implementation of CI at seven automotive suppliers and revealed that after two years, only three obtained partially satisfactory outcomes with further efforts required. A study by the engineering department of Massey University (New Zealand) reports several surveys showing failure rates of between 75\% and 90\% (Goodyer, Grigg and Murti, 2011). By promoting the participation of employees, Kaizen questions the centralization of power within the firm. Kaizen is demanding for the organization as it requires the latter to respond to this significant participation by employees. Garcia et al. (2013) point out that companies with applied Kaizen approaches have reported that workers individually make between 25 and 30 suggestions every year, and 90 per cent of these suggestions are usually implemented. In order to avoid upsetting their intermediate hierarchy as a result of these changes, some companies apply a hackneyed Kaizen by creating implementation specialists, which means they may not share out the existing power. These difficulties are consistent with earlier findings about participation or early attempts to apply Toyotism (Lawler and Mohrman, 1987). Jaca et al. (2014) emphasize that the full implementation of Kaizen is a rarity because it unleashes 
various resistances. However, the literature establishes that it is possible to obtain an effective Kaizen with the emergence of a margin of autonomy for employees in their professional practice (Saurin and Feirrera, 2009), which generates health efficiency (Koukoulaki, 2014).

This heterogeneity in the application of Kaizen means that understanding pitfalls, such as the study of key factors of success is both necessary and difficult. Garcia-Sabater and MarinGarcia (2011), like Jurburg et al. (2015) or earlier Choi (1998), identify several of these pitfalls: lack of training, lack of recognition, marginal decline in gains, lack of valorization of scarcely qualifiable progress or alienation of certain actors (participants, management or CI specialists). For the factors of success, Garcia et al. (2013) identify 21 factors in the literature. Certain studies are more synthetic. In agreement with Netland (2016), Bessant and Francis (1999) distinguish only five factors: management involvement, training, information on decisions taken by the hierarchy in relation to proposals, forms of reward or recognition.

Arezes et al. (2015) note that this diversity in the application of Kaizen can cause a negative impact on health. Kaizen fails to perform its buffer role, which places the economic dimension above the health dimension in the application of Lean and produces negative consequences for the health of employees. In addition, a link between the learning opportunities present in Kaizen and reduced stress has already been demonstrated (Panari et al., 2010). More precisely, a positive impact on health assumes that Kaizen tools are actually in use and incorporate the concerns of employees (Von Thiele Schwarz et al., 2017). Confronted with these contradictory outcomes, Arezes et al. (2015) invite the scientific community to address the link between LP and health in a contingent manner: the reported "disadvantages of LPS implementations reviewed may result from the misunderstanding of the Lean principles. Possibly, they also occur due to partial Lean implementations (when only 
one or two tools were implemented) that may be effective within a specific work setting but not suitable to all possible situations”. If we compare this invitation to our observation that CI is both pivotal and difficult to operate, it seems necessary to further explore the diversity of the forms and realities of Kaizen. In response to this invitation, our work proposes approaching the understanding of LP via the diversity of its application in one of these key dimensions, i.e., Kaizen (or CI).

\section{Methodology}

Based on the reference study by Edmondson and McManus (2007) on the methodological fit, it appears to us that our research objective, the understanding of LP and its effects on the occupational stress of employees, corresponds to a questioning of intermediate theory research. As suggested by Saunders et al. (2014), this type of work corresponds to a situation where there are clearly "provisional explanations" linking the proposed constructs. Edmonson and McManus (2007) point out that one of the first reasons for developing this type of research is to question an established field of work by introducing a new angle of understanding of a phenomenon. Mixed methodologies make it possible to identify new relationships between concepts identified by the literature (Morse, 1991) and also limit the common method bias.

While quantitative methods appear to fit the context of mature and qualitative theories for nascent theories, intermediate theoretical research mobilizes mixed approaches linking quantitative and qualitative methods. Eisenhardt and Graebner (2007) suggest that mixed methodologies are suitable for the study of partially processed phenomena in the literature. This is all the more relevant here for our purpose, that there are mature quantitative tools for measuring stress, but not for continuous improvement, which must be investigate 
qualitatively. We follow the orientation chosen by Longoni et al (2013) in their work on safety at work. This methodological choice allows us both to ensure that we obtain a detailed description of a complex reality, integrating differentiated visions of the same phenomenon (Eisenhardt, 1989) offered by qualitative approaches and to also benefit from the advantages of the approaches i.e., that we will obtain objective data allowing comparisons with both national and sectoral data. This integration of the different forms of data meets the requirement of Bergman (2008) on the quality of mixed methods.

More broadly, this choice of a mixed methodology agrees with Golicic and Davis (2011) for the development of such approaches in the field of production and particularly logistics. The authors emphasize that the complexity of the research questions in this scientific field presupposes the articulation of methodologies. Without this, an understanding of the phenomena is greatly diminished. Admittedly, Greene et al (1989) clearly show that mixed methods can lead to a weakening of the contribution of qualitative and quantitative methods compared to what they can provide when they are used alone, but the authors emphasize that this weakening is largely compensated by the wealth born of the complementarity of the analyzes. Mixed approaches appear to them to bring profitable lessons for the field of the study of production.

\subsection{Sample}

Our sampling is theoretical in that it is made up in relation to key dimensions in the literature mobilized to address the research question. Like Longoni et al. (2013), our sample includes firms of different sizes because this criterion can weigh upon occupational health (Zacharatos et al., 2005). It includes sites of different sizes ranging from 192 to 2,024 employees (see Table 1), but all of them, even when they are legally autonomous, belong to groups or entities 
comprising several thousands of employees. This ensures a critical size in order to acquire knowledge and resources to develop a specific production system. As Table 1 shows, the size of the workshops is also heterogeneous. Unlike Longoni et al. (2013), we chose to confine our sample to industrial cases. This choice is explained by the French context in which Lean management is more particularly present in this sector of activity than in services, which, on another note, have marked specificities. However, we sought the greatest possible diversity in in situ activities, bearing in mind the influence of these activities on the occupational stress of employees.

For the purpose of identifying companies mobilizing Lean management, we relied on a committee of experts. This comprised two researchers, including one of the authors, two members of the Brittany and Pays de Loire regional state agency for the improvement of working conditions, two members of the Regional Directorate of Labor (DIRECCTE) and four consultants specialized in industrial performance and occupational health. It was possible to draw up a partial inventory of industrial Lean companies from the network of partners. Of the 52 cases mentioned, 34 were rejected by the steering committee due to incomplete Lean, 9 refused (mainly due to lack of availability or interest) and 9 were the subject of the study. Only 6 of the 9 case studies enabled dual collection, providing an objective measurement of ambient stress ${ }^{1}$. Only these 6 cases are consequently described here.

Our empirical base consisted of 16 workshops located across 6 companies in the Brittany and Pays de Loire regions in France, in particular due to funding from the corresponding DIRECCTE departments. Without being an exhaustive base, this empirical base is nevertheless solid, exceeding the generally established standards (Yin, 2013/1994). As recommended by Saurin and Ferreira (2009), the workshop will be the basic unit of

\footnotetext{
${ }^{1}$ The work carried out by the expert group is described in detail in the data analysis section.
} 
analysis in our study. Alpenberg and Scarbrough (2016) indicate that it is at this level, that one best observes the role of team dynamics in Lean Management (impact of local management, more or less applied directives, specifics of jobs and groups, etc.). In this respect, we follow the Lean prescription of going to see what happens on the workshop floor (the Gemba principle described by Womack and Jones, 2010). This choice is borne out because there is more variation (and also variance) from one workshop to another in the same company than from one company to another as a whole.

We draw on the work of Longoni et al. (2013), which shows that joint industrial and safety performance is achieved only in companies with significant continuous improvement schemes. For this reason, we concentrated our Lean rating (Table 2) on CI criterion. We nevertheless checked that the four Lean pillars identified by Longoni et al. (2013), namely just-in-time, quality management, preventive maintenance and human resource practices, were significantly implemented. For this reason, like Longoni et al. (2013), we conducted an interview with a person in charge of setting up Lean in each company to verify that we actually found all four pillars. The case studies subsequently allowed us to confirm the initial statements.

\subsection{Data collection}

The case studies were conducted between 2013 and 2015. In accordance with our methodological triangulation guidance and according to a logic of complementarity, we collected both qualitative and quantitative data. For the first data, semi-structured interviews, observations and documentary research were performed. Specifically, 310 employees were interviewed in accordance with the allocation listed in Table 1. At the behest of the companies under study, and given the polemic nature of occupational health issues in France, we were not allowed to record interviews. Given this, for each individual or group interview, a researcher was assigned only for the transcription of the verbal exchanges. In addition, in each 
case, the research team carried out a restitution to the various interviewees of the work for validation and enrichment of the research material.

Aware of the limitations of this methodological constraint imposed by the companies, several precautions were taken in order to obtain the most faithful reproduction of the remarks exchanged. Firstly, the transcripts were completed at the end of the interview. At that juncture, the second researcher present validated and / or enriched this first version, which was then sent to the interviewee for all the individual interviews (the executives). Operators were interviewed by 2 to 4 people according to the focus group methodology (Kruger and Casey, 2000). This involved real-time synthesis, validation and observation of shared opinions and again, there was an enrichment of the empirical material. In addition, the person taking the notes possessed a note-taking capability of 30 words per minute. Finally, the polarization of the interviews around Lean management such as the knowledge of the subject by the transcriber allowed us to limit the loss of words exchanged.

All the parties (trade unions, occupational physicians, employees and management) validated our observations and conclusions. Confidentiality and anonymity were guaranteed. Each individual interview lasted from 45 minutes to 1.5 hour and mainly concerned support functions and guidance. Some interviews were conducted in small groups of operators due to scheduling constraints or incompatibilities in their team. The group interviews lasted between 1 and 2 hours and involved the teams of operators. All interviews dealt with work experience, recent changes, Lean and CI, proximity and senior management, as well as occupational health.

Eight researchers were mobilized in pairs to conduct 92 collective interviews. In order to process the considerable amount of data (about 100 hours of interview and 525 pages of 
transcripts), we were able to rely on real-time syntheses reflecting consensus and disagreements validated by the interviewees (Kruger and Casey, 2000). For our research themes, in particular continuous improvement, consensus and disagreements have been reproduced as verbatim in tables.

For purposes of observation and, in each case, in order to foster insight into working situations, the researchers shared several work breaks with the teams, which provided fruitful discussions and triangulated the sources of information and analysis of the facts identified during the interviews, as well as eliciting new avenues of reflection. These observations, together with a visit to other workshops, allowed us to better understand the nature of the work. We took a particular interest in each workshop at the different moments when CI is being performed: assumption of work stations, visual management and dedicated working groups. In addition, we observed cases of activity flow management. This complemented what the employees had described to us. The research group thus increased its time of observation from half a day to one whole day for each workshop.

Finally, in each of the 6 companies, we were provided access to different documentation specific to the overall situation of the company and for each of the 16 workshops which makes up the basic unit of our analysis. More specifically, we were able to access on-going visual management data and their background, including: productivity data, events, suggestions, feedback from management on suggestions or reported incidents, and work file archives on the Kaizen sites (previous and new locations and the account of the different tests performed). In order to obtain an objective basis for comparing health issues, questionnaires were administered to 334 employees belonging to the relevant workshops. These questionnaires contain the Karasek scales used internationally to characterize occupational stress exposure (Karasek and Theorell, 1992). In doing so, this second sample of 334 employees makes it possible to measure occupational stress more objectively from a scale 
recognized by the literature. It completes the 310 conducted qualitative interviews. Given the anonymity required for the questionnaires, it is not possible to say to what extent the employees interviewed in the focus group and those who answered the quantitative questionnaire were one and the same. However, in both cases we approach a rate of $50 \%$ of respondents and interviews (46\% for interviews and 50\% for questionnaires). This link reflects our mixed methodology according to a complementarity design (Greene et al., 1989). At the end of this collection process, we only use here the data that provide an input to our research question. The next section describes how we extract the relevant data.

In summary, our empirical base is made up of 16 workshops, representing 672 employees of whom 310 were interviewed (mainly group interviews) and 334 that completed a psychometric questionnaire. The anonymity does not allow us to identify which of the 334 employees who completed the questionnaire were also interviewed. The main data are summarized in Table 1 below.

Table 1: Characterization of our sample

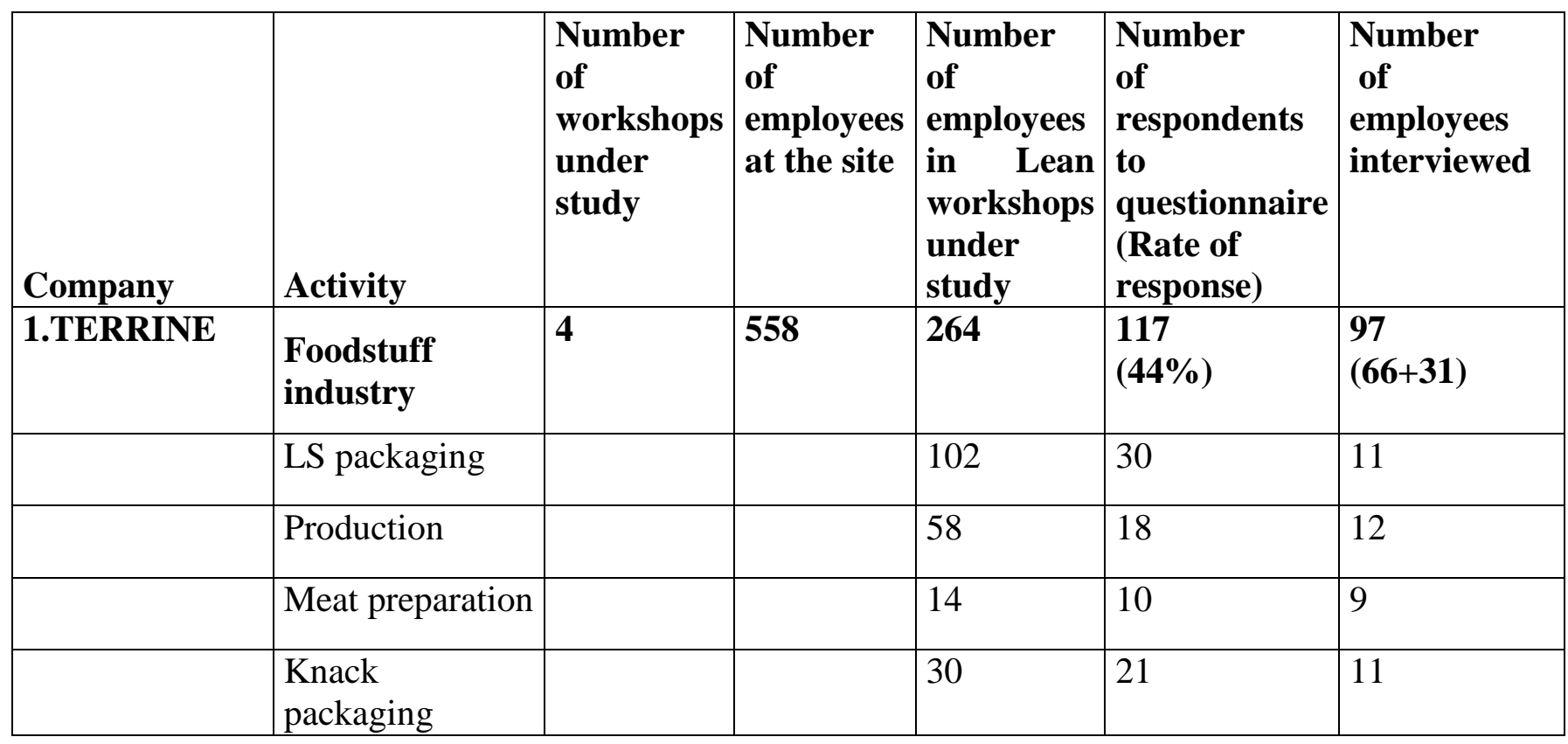




\begin{tabular}{|c|c|c|c|c|c|c|}
\hline \multirow[t]{4}{*}{ 2.APPLIANCE } & \begin{tabular}{|l|} 
Home \\
appliance \\
production
\end{tabular} & 3 & 540 & 89 & \begin{tabular}{|l|}
52 \\
$(58 \%)$
\end{tabular} & 64 \\
\hline & OPF & & & 30 & 17 & 5 \\
\hline & Takt & & & 22 & 9 & 26 \\
\hline & Store & & & 37 & 26 & 25 \\
\hline \multirow[t]{4}{*}{ 3. TRAY } & $\begin{array}{l}\text { Foodstuff } \\
\text { Industry }\end{array}$ & 3 & 192 & 87 & $\begin{array}{l}57 \\
(65 \%)\end{array}$ & 30 \\
\hline & Piercing & & & 49 & 31 & 14 \\
\hline & $\begin{array}{l}\text { Festive } \\
\text { occasions }\end{array}$ & & & 17 & 12 & 4 \\
\hline & Saucisse & & & 21 & 14 & 5 \\
\hline \multirow[t]{3}{*}{ 4.CHICKEN } & $\begin{array}{l}\text { Foodstuff } \\
\text { Industry }\end{array}$ & 2 & 310 & 82 & \begin{tabular}{|l|}
26 \\
$(32 \%)$
\end{tabular} & 29 \\
\hline & Abattoir & & & 41 & 10 & 4 \\
\hline & Packaging & & & 41 & 16 & 10 \\
\hline \multirow[t]{3}{*}{ 5. ROSETTE } & \begin{tabular}{|l} 
Foodstuff \\
Industry
\end{tabular} & 2 & 340 & 71 & \begin{tabular}{|l|}
42 \\
$(59 \%)$
\end{tabular} & 19 \\
\hline & Packaging & & & 22 & 16 & 5 \\
\hline & Casing & & & 49 & 26 & 9 \\
\hline \multirow[t]{3}{*}{ 6.METALICA } & $\begin{array}{l}\text { Construction } \\
\text { industry }\end{array}$ & 2 & 2024 & 79 & $\begin{array}{l}40 \\
(51 \%)\end{array}$ & 71 \\
\hline & Assembly (PPX) & & & 48 & 23 & 26 \\
\hline & Cutting (UFU) & & & 31 & 17 & 26 \\
\hline TOTAL & & 16 & & 672 & \begin{tabular}{|l|}
334 \\
$(50 \%)$
\end{tabular} & $\begin{array}{l}310 \\
(46 \%)\end{array}$ \\
\hline
\end{tabular}

\subsection{Data processing.}

As with Strike and Rerup (2016), our data analysis combines the multiple case approach of Eisenhardt (1989) and the in-depth inductive analysis of Gioia et al. (2013). To our thinking, this means understanding how actors perceive LP (and in particular CI) and to ascertain their feelings about the stress it causes. In both cases, but also by comparing them, we sought to identify the links between LP and occupational stress. 
The analytical phase of our work followed a rigorous process of comparing interpretations by organizing a debate in our committee of experts. Three questions are pivotal to the work of this group: the characterization of CI, industrial performance and occupational stress performance.

The review of the literature led us to pay particular attention to the actual existence of CI as well as its maturity. In this assessment, based on Netland's literature review (2016), we define the maturity of the continuous improvement with three factors: "management commitment and involvement” (hereafter MCI), “training and education”, “employees’ participation and empowerment” (hereafter EPE).

After having verified that all the actors concerned had received training, we focused our attention on the other two criteria. Managerial involvement refers either to the inexistence of continuous improvement meetings (despite the stated intention), to irregular meetings or to regular meetings (Levels 1, 1.5 and 2 or more in our rating). In addition, the degree of employee participation can lead to passive (Rating 2) or dynamic (Rating 2.5) continuous improvement practices. Table 2 below details the ratings' criteria.

Table 2: Rating of the maturity of CI by the expert group

\begin{tabular}{|l|l|}
\hline Rating & Criteria \\
\hline 1 & $\begin{array}{l}\text { Continuous improvement missing } \\
\text { CI is not part of the process (ineffective MCI, ineffective EPE) }\end{array}$ \\
\hline 1,5 & $\begin{array}{l}\text { Folkloric continuous improvement. } \\
\text { The continuous improvement practices do not translate into practice on a } \\
\text { regular basis and the corresponding tools or repositories are incomplete (partial } \\
\text { MCI; ineffective EPE) }\end{array}$ \\
\hline 2 & $\begin{array}{l}\text { Passive continuous improvement } \\
\text { Practices for continuous improvement and participation are planned and } \\
\text { effective, but are based at this stage on the voluntarism of a few actors and } \\
\text { devoid of the organization or the employees fully perceiving the positive }\end{array}$ \\
\hline
\end{tabular}




\begin{tabular}{|l|l|}
\hline 2,5 & $\begin{array}{l}\text { effects. Employee satisfaction is mixed with respect to the functioning of the } \\
\text { system, returns or advances (strong MCI, partial EPE) }\end{array}$ \\
& $\begin{array}{l}\text { Dynamic Continuous improvement } \\
\text { pentinuous improvement practices are dynamic: regular, followed by } \\
\text { to go beyond limited adjustments and to challenge structuring decisions } \\
\text { (strong MCI, strong EPE) }\end{array}$ \\
\hline
\end{tabular}

Based on the data collected and gathered for the occasion (documentary analysis, field observations, qualified interviews), the expert group had to decide on the CI level and the Lean performance on a five-point scale $(1,1.5,2,2.5,3)$ (Table 2) but no workshop was granted 3. To limit influence biases, each member of the group made the estimate by having all the data available and without knowing the evaluation of the others. The deviations did not exceed one level.

Table 3 below describes the CI maturity as assessed by the expert group and significant verbatim from employees' interviews as an illustration.

Table 3: Continuous Improvement maturity for each workshop

\begin{tabular}{|l|l|l|}
\hline Workshop & CI maturity & $\begin{array}{l}\text { Verbatim illustrating the perceived capacity to take } \\
\text { into account field problems by the hierarchical line } \\
\text { (dynamism of CI) }\end{array}$ \\
\hline $\begin{array}{l}\text { 1.TERRINE LS } \\
\text { packaging }\end{array}$ & $\begin{array}{l}\text { Things are better. We used to moan about not having } \\
\text { leaders. We had a supervisor for the team, but there } \\
\text { were other ones so we never knew who to turn to! Now } \\
\text { we know! (an operator). }\end{array}$ \\
\hline 2. APPLIANCE & $\begin{array}{l}\text { Things are better now. Our boss is N., things are clear } \\
\text { with her. (an operator). }\end{array}$ \\
\hline 2,500 & $\begin{array}{l}\text { I have never come across such humane and open- } \\
\text { minded leaders, they try to understand the problems, } \\
\text { and give a helping hand (an interim). } \\
\text { The hierarchy is o.k. ... We have a lot of opportunities } \\
\text { for the three levels ... (a driver). } \\
\text { They are listening, they try to get to know the problems } \\
\text { so to help us (an operator). }\end{array}$ \\
\hline
\end{tabular}




\begin{tabular}{|c|c|c|}
\hline $\begin{array}{l}\text { 3.TRAY piercing } \\
\text { \& packaging. }\end{array}$ & 2,500 & $\begin{array}{l}\text { The managers work efficiently, some will push a bit and } \\
\text { others are more laid back. Sometimes we do have too } \\
\text { much work [and our manager] will lend us a hand } \\
\text { (cutting operator). } \\
\text { Yes, we talk about this in meetings, it's good, we can } \\
\text { say things; we can exchange ideas, OK but do we ever } \\
\text { get the changes? (packaging operator). } \\
\text { They do not always take into account our suggestions } \\
\text { but generally speaking... it is good and I'll take the } \\
\text { positives (packaging operator). }\end{array}$ \\
\hline $\begin{array}{l}\text { 4.CHICKEN } \\
\text { Packaging }\end{array}$ & 2,500 & $\begin{array}{l}\text { In my workplace, there is communication all through } \\
\text { the day. For me, listening to people is the key to } \\
\text { success for everything (head of packaging workshop). } \\
\text { Today we have T-cards to get the problem upstairs and } \\
\text { behind they do a follow-up (operator). } \\
\text { The Visual Management meetings make it easier to } \\
\text { express ourselves(operator). } \\
\text { Before we daren't speak out or it was just some words } \\
\text { but no back up (operator). }\end{array}$ \\
\hline $\begin{array}{l}\text { 5.TRAY } \\
\text { Festive }\end{array}$ & 2,500 & $\begin{array}{l}\text { The new organization is less physical and less } \\
\text { repetitive ... The organization is good on the whole, we } \\
\text { do a good job because the atmosphere with colleagues } \\
\text { is good and that counts enormously. The position is } \\
\text { made to suit each of us (operator). } \\
\text { Now we function at the same speed, it is more regular, } \\
\text { it is less stressful and less tiring. We rotate, we know } \\
\text { how to do everything, it is less tiring, it is a good thing } \\
\text { and works well (operator). } \\
\text { At first, we said to ourselves: this is not possible- we } \\
\text { are getting nowhere and, in fact, we are doing more. At } \\
\text { the time it was not easy, we had the feeling of being } \\
\text { turned into snails, as before we had to do things fast, } \\
\text { very fast. We were all over the place (women } \\
\text { operators). } \\
\text { There were also some who did less than others and who } \\
\text { made less efforts, whereas now everyone is shifting } \\
\text { places (women operators). }\end{array}$ \\
\hline $\begin{array}{l}\text { 6.TRAY } \\
\text { saucisse }\end{array}$ & 2,500 & $\begin{array}{l}\text { We have improved a lot in the work, everything has to } \\
\text { be in its place... The weekly meetings are good, they } \\
\text { allow us to be more informed about the life of the } \\
\text { company and we can express ourselves. One good } \\
\text { point: the work is nice ... The new automatic line is } \\
\text { good, I love it and we waste less time (saucisse women } \\
\text { operators). } \\
\text { In winter: The manager gives instructions and another }\end{array}$ \\
\hline
\end{tabular}




\begin{tabular}{|c|c|c|}
\hline & & $\begin{array}{l}\text { comes by after and gives us other instructions. So, we } \\
\text { do not know what to do. }\end{array}$ \\
\hline $\begin{array}{l}\text { 7.TERRINE } \\
\text { Production }\end{array}$ & 2,00 & $\begin{array}{l}\text { If you open your mouth too much you are told that "if } \\
\text { you are not happy there are always people waiting } \\
\text { outside "(operator). } \\
\text { I personally have the feeling that the guy in charge } \\
\text { shirks his responsibility with these grades (operator). } \\
\text { We used to talk about how to do things, we could argue } \\
\text { points, we could negotiate. Now we are given a grade } \\
\text { and we have to sign it (operator). }\end{array}$ \\
\hline $\begin{array}{l}\text { 9.TERRINE } \\
\text { Knack packaging }\end{array}$ & 2,000 & $\begin{array}{l}\text { [New line that causes pain and discontent] } \\
\text { Before it was easier, we have been busting our guts for } \\
\text { a year now it is a hard machine, it ain't made for } \\
\text { human beings } \\
\text { From the beginning, we always said that the new } \\
\text { machine was not right } \\
\text { I'd like to go back, get back our old machines, we do } \\
\text { not even have time to exchange a word, we do not have } \\
\text { the time to work. It's a real drag, } \\
\text { We do not have enough meetings to see what's } \\
\text { happening to the other teams, we do not have any } \\
\text { exchange, there is no time when the women drivers are } \\
\text { among colleagues (operator). }\end{array}$ \\
\hline \begin{tabular}{|l|} 
8.TERRINE \\
meat preparation
\end{tabular} & 2,000 & $\begin{array}{l}\text { I am free to manage my work (operator). } \\
\text { [workshops for continuous improvement] this is } \\
\text { helpful but not essential } \\
\text { Before, we had regular visits every fortnight now } \\
\text { nothing [for a month and a half] }\end{array}$ \\
\hline $\begin{array}{l}\text { 10. APPLIANCE } \\
\text { OPF }\end{array}$ & 2,000 & $\begin{array}{l}\text { We once had a super guy as a pilot, always ready to } \\
\text { help, to come around to the boiler-he wasn't scared .. } \\
\text { Today the driver stresses us out ... Even if it is not his } \\
\text { role we could do with some help from time to time... } \\
\text { But he does not know the product and he pressurizes us } \\
\text { without realizing ... He made me cry twice before the } \\
\text { holidays... We always feel like we are not doing } \\
\text { enough ... There is a lack of trust (operator). }\end{array}$ \\
\hline $\begin{array}{l}\text { 11.APPLIANCE } \\
\text { Takt }\end{array}$ & 2,000 & $\begin{array}{l}\text { There is not much communication. We have tried } \\
\text { saying what we think but it doesn't mean anything. } \\
\text { Everything is decided at the O\&M level. Yet a } \\
\text { communication working group was set up. But things } \\
\text { just got worse. (operator). } \\
\text { Assuming one's workstation. It concerns us without } \\
\text { concerning us. He notes the suggestions but that's all. } \\
\text { (operator). }\end{array}$ \\
\hline
\end{tabular}




\begin{tabular}{|c|c|c|}
\hline $\begin{array}{l}\text { 12.ROSETTE } \\
\text { Packaging }\end{array}$ & 1,500 & $\begin{array}{l}\text { There was good work being done. But even so, we } \\
\text { could have held a meeting to explain why the project } \\
\text { did not succeed (manager). } \\
\text { We did an experiment } 2 \text { years ago, Project XXX, we } \\
\text { worked darned hard and we earned ourselves a nil } \\
\text { result (operator). } \\
\text { They preferred speed to save time, but as for gestures ... } \\
\text { we are going backwards (operator). }\end{array}$ \\
\hline $\begin{array}{l}\text { 13.METALICA } \\
\text { UFU Cutting }\end{array}$ & 1,500 & $\begin{array}{l}\text { We did training on Lean, it was quite tough but apart } \\
\text { from that for me, we didn't get anywhere. No wastes? } \\
\text { For me that's just not happening (operator). } \\
\text { We have meetings every day. We have a short briefing } \\
\text { of } 5 \text { minutes. For CI, this takes place in the works with } \\
\text { us all having to remain standing for } 5 \text { minutes and } \\
\text { hearing nothing. What we learn is about the outside } \\
\text { (operator). } \\
\text { At our level, there is not much left of Lean. It would } \\
\text { require much more efficient follow-up (operator) } \\
\text { In terms of organization they do not make enough } \\
\text { contacts with those in the field, they make their } \\
\text { decisions at the top without inquiring below. They use } \\
\text { outside speakers ... (operator). } \\
\text { For the latest projects, they asked for our opinion after } \\
\text { things had been done or ordered .... (operator). } \\
\text { We have a Lean engineer but never see him, they } \\
\text { passed by at the beginning but now we see none of them } \\
\text { (operator). } \\
\text { They listened to the problems of other companies } \\
\text { when they had been told of ours long before(operator). }\end{array}$ \\
\hline $\begin{array}{l}\text { 14.ROSETTE } \\
\text { Cover }\end{array}$ & 1,500 & $\begin{array}{l}\text { There is not much decided, we make proposals, but we } \\
\text { do not know if what is said is good or bad, or if we will } \\
\text { do it. Information about the management is somewhat } \\
\text { lacking, because they must know what they were } \\
\text { planning to do, we were never asked how we intended } \\
\text { to do things, they said nothing to us, I proposed } \\
\text { something for the carpets, there are two guys who are } \\
\text { doing nothing, you have to put one on each end, like } \\
\text { that everyone wouldn't have to sprain their shoulders, } \\
\text { and they do nothing. One wonders why on earth one } \\
\text { should start a working group (operator). }\end{array}$ \\
\hline $\begin{array}{l}\text { 15.METALICA } \\
\text { PPR } \\
\text { Assembly }\end{array}$ & 1,500 & $\begin{array}{l}\text { We are not consulted, when they built the new } \\
\text { workshop it was a nightmare and it was impossible to } \\
\text { work (operator). } \\
\text { No communication between supervisor and operator } \\
\text { (operator). }\end{array}$ \\
\hline
\end{tabular}




\begin{tabular}{|l|l|l|}
\hline & & $\begin{array}{l}\text { They bugged us for 2 years with Lean, and now we hear } \\
\text { no more about it (operator). }\end{array}$ \\
\hline $\begin{array}{l}\text { 16. CHICKEN } \\
\text { Abattoir }\end{array}$ & $\begin{array}{l}\text { An opening dialogue but too much data that does not } \\
\text { speak to people (operator). } \\
\text { My fear is to drown them in the numbers and then they } \\
\text { may get tired of seeing the same thing all the } \\
\text { time (manager). } \\
\text { [Call for regulation]: For those in charge, it's their } \\
\text { role. It is not normal to leave people like this... it is the } \\
\text { product that will suffer after (abattoir operators). }\end{array}$ \\
\hline
\end{tabular}

The expert group was also asked to proceed with a second rating, i.e., industrial performance defined as the productivity gains observed in the workshop. The expert group positioned itself by taking into account sectoral and trade components to assess the extent of these productivity gains. Our challenge was to verify whether the preservation of employee health is not conducted through a less demanding Lean in terms of industrial performance but thanks to the quality of continuous improvement. It is therefore a control variable. Although the indicators available or sought after differ from one case to another (overall equipment effectiveness, production lead times, etc.), the expert group decided on the existence of significant performance gains taking into account the previous position, the requirements of management and the development of the sector of activity. Level 2 is the minimum to consider if Lean has translated into performance gains in line with what is expected. At Level 1, the expert group considered that the process does not produce the generally expected performance gains of Lean. At Level 3 productivity gains are estimated to be remarkable. Levels 1.5 and 2.5 are intermediate situations.

Finally, for the last variable, given that the health performance and the comparability of health-related social data are difficult (partial data, calculation methods, etc.), we relied exclusively on psychometric questionnaires. Unlike data such as absenteeism, these better quantify exposure at the time of the survey and are less sensitive to other factors. Here we use 
the scales developed originally by Karasek (1979) and also Karasek and Theorell (1992). These scales make it possible to measure the perceived exposure to stress from an imbalance between demand (job requirement, job requirement) on the one hand and the latitudes (autonomy) or social support on the other. Strain is the situation where demand outstrips the median of the reference population and where the latitudes are below the median of the reference population. Isotrain is a strain situation to which is added social and managerial support lower than the median of the reference population. The link between strain and isotrain situations with occupational diseases has been widely established in the literature (Karasek and Theorell, 1992). In this study, we consider isostrain, which constitutes the most harmful situation in terms of exposure to stress.

The French SUMER 2010 national survey $^{2}$ served us as a reference population. The identification of employees in an isotrain situation can be quantified to indicate the percentage in this situation in a workshop and also, the percentage that is not in this situation, and what we term hereafter as "health performance" (100 -\% isostrain). As a guideline, we verified the relevance of the link between continuous improvement and health performance with a significant ANOVA at the 5\% threshold (0.032).

\section{Results.}

\footnotetext{
${ }^{2}$ The national SUMER survey (Medical Surveillance of Exposures to Occupational Risks) is a periodical survey on working conditions that began in 1987 (then 1994, 2003 and 2010) and is supervised by the Ministry of Labor. Administered by occupational physicians, the survey is representative of the 22 million French employees with 47,983 respondents. It makes it possible to provide sector-specific references to stress exposures.
} 
For the following tables, after the health performance indicator, we show the reference indicator combining sector and occupation using the Sumer 2010 database. Firstly, we extracted sector by sector, the health performance level for the population of workers. This figure was adjusted for the packaging workshops in order to make them comparable with the production workshops. Again, the correction was made using the Sumer 2010 database and leads to an addition of 6.5 to the benchmark.

Where the deviation is greater than one standard deviation, the rating is "sign. above ++" (or sign below - -), where the deviation is greater than $1 / 4$ standard deviation, the rating is "somehow below or above" and if not, we consider that we are within the average. We follow a method of data reduction similar to that of Longoni et al. (2013) on occupational safety issues.

Our presentation of the results is divided into two parts. In the first part, we will provide a global view of the links between occupational stress and LP. As a second step, we will carry out a subgroup analysis in order to deepen our understanding of the data and further integrate the context. This will lead us to analyzing particular cases by integrating qualitative elements.

\subsubsection{Global propensity of the workshops}

As shown in Figure 1 below, our study on workshops reveals that the maturity of CI and health performance shares a complex relationship. A U-shaped relationship appears. The Sumer 2010 national survey allows us to locate these results. The isostrain of the sectors of activity covered by our survey for workers is $34.7 \%$, i.e., in our graph a health performance of 65.3\% (workers who are not in isostrain) represented by dotted lines. Although poor Lean is accompanied by better occupational stress for employees, its dynamic development is equally so, but with a productive performance that probably provides a better chance of sustainability for the company. This U-shaped curve tallies with the results of Conti et al. (2006), with a 
different methodological approach, which confirms the validity of this result. Whereas the work in question may suggest that it is mainly a curve of experience and the shock of change, we seek to explain this result by the characteristics of the continuous improvement dynamic that may be a necessary condition for advanced lean (Knol et al., 2018). Overall, the workshops studied show that the introduction of CI is insufficient. Worse, the regular CI (but not dynamic) is associated with a deterioration in the health situation. On the other hand, situations of continuous dynamic improvement (see Table 2) make it possible to combine Lean, performance and health.

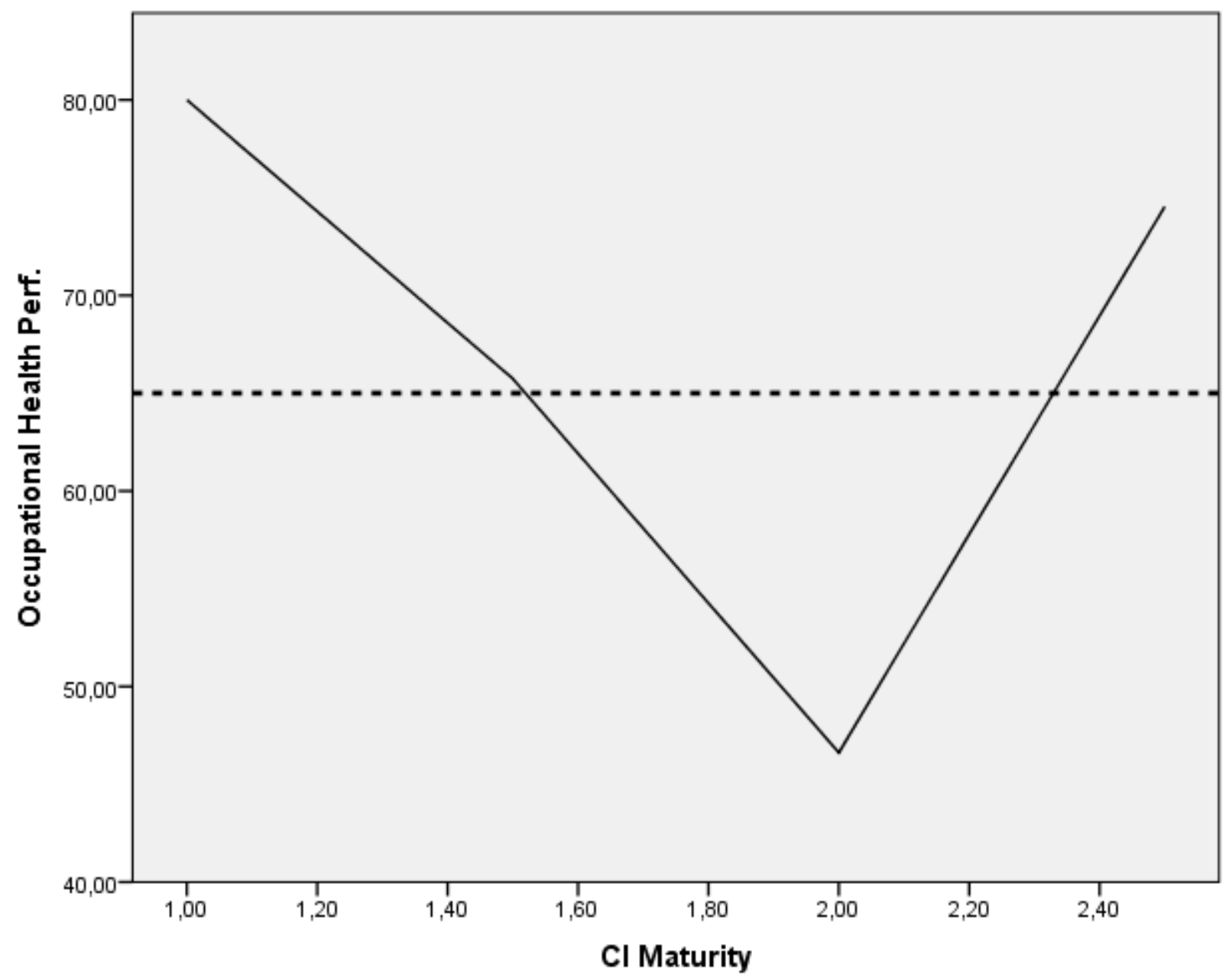

\subsection{2 - Analysis per group of workshops}

The data are itemized into three tables in relation to the maturity of the CI (table 4, 5 and 6 below): 
Table 4 - dynamic continuous improvement

\begin{tabular}{|l|l|l|l|l|l|}
\hline Workshop & $\begin{array}{l}\text { Maturity } \\
\text { of the CI }\end{array}$ & $\begin{array}{l}\text { Industrial } \\
\text { performance }\end{array}$ & $\begin{array}{l}\text { health } \\
\text { performance }\end{array}$ & $\begin{array}{l}\text { Sector+ } \\
\text { occupation } \\
\text { reference }\end{array}$ & Rating \\
\hline $\begin{array}{l}\text { L.TERRINE } \\
\text { LS } \\
\text { packaging }\end{array}$ & 2.5 & 3,000 & 76.7 & 63.6 & Sign. Above ++ \\
\hline $\begin{array}{l}\text { 2.APPLIAN } \\
\text { CE } \\
\text { store }\end{array}$ & 2.5 & 2,500 & 80.8 & 69.3 & Sign. Above ++ \\
\hline $\begin{array}{l}\text { 3.TRAY } \\
\text { piercing } \\
\text { packaging }\end{array}$ & 2.5 & 2,000 & 83.87 & 73.7 & Sign. Above ++ \\
\hline $\begin{array}{l}\text { 4.CHICKEN } \\
\text { packaging }\end{array}$ & 2.5 & 1,000 & 75 & 66.9 & Sign. Above ++ \\
\hline $\begin{array}{l}\text { 5.TRAY } \\
\text { Festive }\end{array}$ & 2.5 & 3,000 & 66.7 & 67.2 & Average +/- \\
\hline $\begin{array}{l}\text { 6.TRAY } \\
\text { saucisse }\end{array}$ & 2.5 & 2,500 & 64.3 & 67.2 & Somehow below- \\
\hline \hline
\end{tabular}

It appears that four of the six Level 2.5 workshops are significantly above average in terms of health. The fifth remains average. The sixth is slightly below. Overall, these data show that dynamic CI minimizes health and does so better than the level of comparison (sector and activity). The slightly below-average workshop experienced a situation of team conflict, independent of LP, which may explain the slightly negative outcome.

The workshop at the top of our table (Workshop 1) was confronted with a significant process of transformation: from an open workplace, where communication was easy, to work partitioned for reasons of hygiene. The ongoing improvement process has made it possible to raise the early concern of employees about this issue. The company has been very responsive by initiating a psychosocial risk prevention approach, by organizing exchange and userfriendliness times to preserve links or by equipping each operator with remote communication facilities so that they do not remain alone when faced with a difficulty.

When CI is passive, both health and industrial performance fall significantly (Table 5) 
Table 5 - Passive continuous improvement

\begin{tabular}{|l|l|l|l|l|l|}
\hline Workshop & $\begin{array}{l}\text { Maturity } \\
\text { of the CI }\end{array}$ & $\begin{array}{l}\text { Industrial } \\
\text { performance }\end{array}$ & $\begin{array}{l}\text { health } \\
\text { performance }\end{array}$ & $\begin{array}{l}\text { Sector+ } \\
\text { occupation } \\
\text { reference }\end{array}$ & Rating \\
\hline $\begin{array}{l}\text { 7.TERRINE } \\
\text { Production }\end{array}$ & 2,00 & 3,000 & 61.1 & 57.1 & $\begin{array}{l}\text { Somehow above } \\
+\end{array}$ \\
\hline $\begin{array}{l}\text { 8.TERRINE } \\
2 \begin{array}{c}\text { Meat } \\
\text { preparation }\end{array}\end{array}$ & 2.00 & 2,000 & 70 & 57.1 & Sign. Above ++ \\
\hline $\begin{array}{l}\text { 9.TERRINE } \\
\text { 2 Knack } \\
\text { packaging }\end{array}$ & 2,000 & 2,000 & 33.3 & 63.6 & Sign below - - \\
\hline $\begin{array}{l}\text { 10.APPLIA } \\
\text { NCE OPF }\end{array}$ & 2,000 & 2,000 & 35.3 & 72.8 & Sign below - - \\
\hline $\begin{array}{l}\text { 11.APPLIA } \\
\text { NCE Takt }\end{array}$ & 2,000 & 2,500 & 33.3 & 72.8 & Sign below - - \\
\hline \hline
\end{tabular}

For Level 2, non-dynamic continuous improvement workshops, the situation is the reverse of the previous one. LP appears very largely negative with one exception (Workshop 8). Workshop 7 is slightly above the sectoral reference but still below the average of the study sectors as a whole (65.3\%). How can one explain that Lean with passive continuous improvement is so negative, especially in comparison with folkloric or absent CI? The Takt example of Workshop 11 is very revealing. On the one hand, operators are confronted with the demands of a powerful upswing in Lean, in this case the Takt time system. On the other hand, they are faced with the requirement of holding continuous improvement meetings. However, their experience is that " There is not much communication. We have tried to say what we think but it doesn't mean anything. Everything is decided at the O\&M level. Yet a communication working group was set up. But things just got worse. (operator)". In other words, the Lean takt time has become a Taylorian task-time, managed and devised by the O\&M department but with the increased demands of production engineering and, above all, regulatory attendance at unproductive continuous improvement meetings. Far from being a support, CI is thus an extra workload, which is even meaningless and frustrating. 
Workshop 8 presents an exception that can be explained by considering the specifics of the workshop. On the one hand, the intensity of the work is less significant than in the rest of the company (Demand as in Karasek at 20.8 against 24.14 for the whole company). Moreover, as the interviews and the observation demonstrate, the decision latitude at work is substantial (also shown by the data of the questionnaire about decision latitude to 63.8 against 59.9 for the whole company). Last and most importantly, this comes from a committed but defensive body, united by belonging to one trade i.e., the meat profession, which constitutes an identity and arouses solidarity and collective protection. There is no CI dynamic but other moderating processes.

We conclude with the more contrasting situation of absent or folkloric CI (table 6):

Table 6 - folkloric $(1,5)$ or absent (1) continuous improvement

\begin{tabular}{|c|c|c|c|c|c|}
\hline Workshop & $\begin{array}{l}\mathrm{CI} \\
\text { maturity }\end{array}$ & $\begin{array}{l}\text { Industrial } \\
\text { performan } \\
\text { ce }\end{array}$ & $\begin{array}{l}\text { Health } \\
\text { performan } \\
\text { ce (stress) }\end{array}$ & $\begin{array}{l}\text { Sector+ } \\
\text { occupation } \\
\text { reference }\end{array}$ & Rating \\
\hline $\begin{array}{l}\text { 12.ROSETTE } \\
\text { Packaging }\end{array}$ & 1,500 & 2,000 & 68.7 & 73.7 & $\begin{array}{l}\text { Significantly below } \\
\text { - - }\end{array}$ \\
\hline $\begin{array}{l}\text { 13.METALIC } \\
\text { A UFU } \\
\text { Cutting }\end{array}$ & 1,500 & 2,200 & 82.4 & 73.2 & $\begin{array}{l}\text { Significantly above } \\
++\end{array}$ \\
\hline $\begin{array}{l}\text { 14.ROSETTE } \\
\text { Covering }\end{array}$ & 1,500 & 2,000 & 42.3 & 67.2 & Sign below - - \\
\hline
\end{tabular}




\begin{tabular}{|l|l|l|l|l|l|}
\hline 15.METALIC & & & 69.6 & 73.2 & Somehow below - \\
A PPR & 1,500 & 2,000 & & & \\
Assembly & & & & & \\
\hline 16.CHICKEN & 1,000 & 1,000 & 80 & 60.4 & Sign above ++ \\
Abattoir & & & & & \\
\hline
\end{tabular}

The situation remains negative for Level 1.5 continuous folkloric improvement, although in smaller proportions than for the subsequent level, as we saw from the curve. These results bear out the hypothesis that the effective introduction of Lean is generally mirrored in an intensification of work that is detrimental to health. Workshops 12 and 14 reflect this situation of a Lean regressive tool for operators. In particular, Workshop 14 is confronted with a Kaizen blitz (sic) approach, which consists of obtaining rapid performance gains, carried out by an external firm and the remuneration of which is based on the percentage of the gains obtained. Again, as in the case of the O\&M department, there is a substantial heteronomy of work.

The situation in Workshop 16, where Lean and CI are essentially unapplied prescriptions, lends support to the finding. Although we have only one case in this situation, it adds weight to the idea that the absence of Lean (Level 1) is preferable to a complete Lean which is continuous non-dynamic (2.0) or unapplied (1.5). Let us note that the deleterious effects of an incomplete Lean are probably mitigated by our choice of organization with a demonstrated concern for occupational health (case selection requirement).

Among this group of workshops, it is important to consider the seemingly paradoxical situation of Workshop 13. Health performance is excellent in our sample but also in the sector. Lean is applied to it in tool mode and as a breathless continuous improvement scheme, given the resistance of the group. This is a very much unionized and supportive working 
group, which, because of the company's extensive use of subcontracting (large fluctuating projects), provides a guarantee of continuity and organizational memory. This group is thus able to resist what could be harmful in Lean, but also to discuss, in a manner that largely escapes the managerial line, adjustments and improvement in work.

\section{Discussion}

The aim of this research is to answer the following question: what is the impact of the implementation of continuous improvement upon the occupational stress of employees within the framework of Lean management?

This question is part of the wider debate around the impact of LP on the health of employees. Based on 16 workshops in 6 companies, with 672 employees, of which 310 were interviewed and 334 filled questionnaires, this research comprises both theoretical and practical implications but also limitations.

1 - Theoretical contribution of the research.

In the first instance, this research shows that under certain conditions, Kaizen may produce positive effects upon the occupational stress of employees. This result complements the existing literature that has so far focused on the physical dimension of health (Arezes et al., 2015; Longoni et al., 2014). Moreover, this research validates the relevance of a contextualized reading of Kaizen. The processes and quality of implementation are essential (Goodyer, Gigg and Murti, 2011; Westgaard and Winkel, 2011). Our work validates the shift away from any univocal reading of Kaizen. The latter is not by nature good or bad for the occupational stress of employees. An ill-mastered application can lead to a degradation of the occupational stress of employees. Accordingly, this explains past paradoxical results suggesting a negative link between Kaizen and employee health. Conversely, a dynamic Kaizen meeting the directions set by the creators of Lean management, means an 
improvement in the occupational stress of employees (Monroe et al., 2012; Vieira et al., 2012).

Secondly, this research echoes several calls upon the scientific community (Kouloulaki, 2014; Bamber et al., 2014; Von Thiele Schwarz et al., 2017) to no longer carry out work on the whole of Lean management but on each of its guiding principles. More importantly, it precisely identifies the effects of two essential practices (the participation of the hierarchy and the commitment of the employees) with one of the key principles of Lean management (Kaizen or CI) on health. This focus firstly confirms the positive impact of these practices already identified in the literature (Bessant and Francis, 1999; Garcia et al., 2013; Netland, 2016; Oropesa-Vento et al., 2016). Secondly, this focus shows that of the impacts of Kaizen on the occupational stress of employees, it is practices such as taking into account the opinions of employees, power sharing, and the involvement of all to achieve gradual improvements that play a paramount role. The interviews we conducted show that dynamic Kaizen makes it possible to deal quickly with or even to anticipate the factors of irritation or impediment to work. Not taking it into account or making only a partial or diverted application (Netland, 2016; Garcia et al., 2013) deteriorates the occupational stress of employees. This is not so much a matter of applying or integrating all the returns of the employees but to give them full consideration and to give back to the employees the consideration that they are expecting (to explain the decisions especially when they deviate from what emerges from the participation). Conversely, making it dynamic and shared in workshops as well as outside, triggers a dynamic of participation contributing to the occupational health of employees. Although focused on improving work and flows, a dynamic continuous improvement approach allows us to appraise what may affect the occupational stress of employees (stress). This result confirms the importance of employee autonomy (Olivella et al., 2008; Seppala and Klemola, 2004) and extends the findings of 
Longoni et al. (2013), which emphasized the key role of HR practices in the health and safety of employees, in the case of occupational stress.

Thirdly, our work also helps to underline the basis of this participatory dynamic. As the literature indicates (Lawler and Mohrman, 1987), participation implies a supportive context. This work shows the crucial role of time in the launch, organization and perpetuation of this dynamic. The study of the workshops with a dynamic CI facility shows that they all went through a "passive" phase, where the effort to operate the facility was not returned, neither as regards the operators, nor the management. This passive phase can be shortened by the initial enthusiasm. The possibility for both employees and management to quickly see concrete results is an essential element in the sustainability of the facility in question. There is thus an organizational learning challenge (Argyris and Schon, 1978), pointed out by Liker (2004) as Lean's ultimate goal. To a maturity of Lean often centered on the tools, one may oppose a collective maturity of which CI is the workers' linchpin.

More broadly, this research contributes to the debate on the impact of Lean management on the health of employees. Without revisiting what has just been stated, this research is fully in line with the third phase identified by Kouloulaki (2014) on Lean management work, which emphasizes that Lean management is not by nature good or bad and that it should be studied more precisely by focusing on one of its key practices. Focusing on the participation of employees and the hierarchy, our work confirms the results of Westgaard and Winkel (2011), Conti et al. (2006) as Dalgard et al. (2009) stating that, provided they are dynamic, CI facilities are a place for regulating and balancing stress and as for questions pertaining to safety (Longoni et al., 2013) or perhaps to musculoskeletal disorders.

Finally, this research contributes to the field of work on Lean management by proposing an empirical response to the various voiced criticisms. Indeed, several authors specify that the 
relationship to the field in LP work is often biased due to the systematic use of a questionnaire approach (Conti et al., 2006; Lewchuk et al., 2001) with case studies considering the opinions only of the leaders in Lean management (Saurin and Ferreira, 2009). There is therefore seemingly and, paradoxically, something critical missing from research on Lean management i.e., the employees who ensure its existence. Longoni et al. (2013) call on the scientific community to take account of this shortcoming by coming down to earth and questioning the actors of everyday Lean management. This research fully meets this call. The interviewed workers were placed in a situation of complete freedom as both anonymity and the confidentiality of the exchanges were guaranteed. In addition, the presence of the trade unions in several sites allowed employees to have recourse in the event of a problem, but this did not prove necessary.

\section{2- Managerial Implications}

This research has real practical implications. By highlighting the existence of a particularly destructive and passive LP for employees, which leads to more stress, this research invites companies and training organizations to re-assess the content of their curriculum in order to incorporate expertise in terms of human resources. At a deeper level, another way would be to get profiles of technical expertise and social sciences to work together in order to generate an active CI. The integration of this new form of expertise at the grassroots level would make it possible to guarantee organizations against the many CI failure factors identified in the literature (Choi, 1998; Bessant and Francis, 1999; Garcia-Sabater and Marin-Garcia, 2011; Jurburg et al., 2015; Netland, 2016) such as the lack of regularity, excessive vertical management, ineffective tracking of problems or lack of financial support for required change. 
It could then be possible to integrate mechanisms of efficiency in economic and health terms such as the concrete running of participative times, the taking into account of the discourse of operators and the management of operational feedback. At an organizational level, they can support comprehensive engineering to drive continuous improvement, monitor its effects and even measure the level of involvement of operators or managers. In particular, they can guarantee that each point being raised is subject to arbitration (favorable or unfavorable) and does not remain on hold, as is often seen in the field. These 'pending' upturns cause a lot of frustration and the belief that it is all to no avail. Finally, they can be the guarantors that decisions and even deadlocks are the subject of regular communication.

\section{3- Limitations and future research opportunities.}

This research includes several limitations that constitute as many fertile lines of research. Firstly, this research relies on a single data entry. Longitudinal research design should be put in place to understand the relationship between continuous progress and health over time. The integration of an international dimension into data collection appears as an additional element that we believe must be taken into account. Secondly, it is seemingly necessary to further deepen not only insight into lean and its various components but also their development over time (which would allow the longitudinal approach). Such an approach would first and foremost help to better understand when and how health issues are addressed or not in CI. In addition, it would make it possible to diachronically integrate the understanding of the different facets of model organization (Taylorism, Fordism, Sociotechnical) and the situation in the organization prior to Lean management so as to determine how it influences occupational health as well as the worker's mindset and how it promotes change. The development of tools could then be considered for monitoring the dynamic of CI and measuring its effects in terms of health and performance. Thirdly, it seems appropriate to 
include in the analysis the type of governance of organizations. In fact, employee incentive plans as well as managerial involvement assume that shareholders are willing to tolerate power sharing and being involved in the long term to create bonds of trust between the various stakeholders. It may therefore be relevant to compare family businesses and groups with internationally spread capital. Finally, as suggested by Von Thiele Schwarz et al., (2017), the theoretical framework of person-fit theory (Kristof-Brown et al., 2005) could provide a promising theoretical perspective to better understand the simultaneous Kaizen link with the other founding principles of Lean management such as the managerial practices comprising it. It may then be possible to identify preconditions for a successful implementation of Kaizen for the health of employees, be this mental or physical. 


\section{References}

Alpenberg, Jan, and Paul D. Scarbrough. 2016. "Exploring communication practices in lean production." Journal of Business Research 69 (11): 4959-4963.

Alves, Anabela C., Jose Dinis-Carvalho and Rui Sousa. 2012. "Lean production as promoter of thinkers to achieve companies’ agility.” Learning Organization 19 (3): 219-237.

Argyris, Chris, and Donald Schon. 1978. "Organizational learning: A theory of action approach." Reading, MA: Addision Wesley.

Arezes, Pedro M., José Dinis-Carvalho, and Anabela Carvalho Alves. 2015. "Workplace ergonomics in lean production environments: A literature review." Work 52(1): 57-70.

Bamber, Greg, Pauline Stanton, Timothy Bartram and Ruth Ballardie. 2014. "Human resource management, Lean processes and outcomes for employees: Towards a research agenda.” The International Journal of Human Resource Management 25(21): 2881-2891.

Bergman, Manfred M., ed. 2008. Advances in mixed methods research: Theories and applications. London: Sage.

Bessant, John, and David Francis. 1999. "Developing strategic continuous improvement capability." International Journal of Operations \& Production Management 19(11): 11061119.

Bruno, Robert, and Lisa Jordan. 2002. "Lean production and the discourse of dissent." Working 6(1): 108-134.

Choi, Thomas. 1998. "The Successes and Failures of Implementing Continuous Improvement Programs: Cases of Seven Automotive Parts Suppliers.” In Becoming Lean, edited by Jeffrey Liker, 409-455, Portland (Oregon): Productivity Press.

Conti, Robert, Jannis Angelis, Cary Cooper, Brian Faragher, and Colin Gill. 2006. "The Effects of Lean Production on Worker Stress.” International Journal of Operations and Production Management 26 (9): 1013-1038.

Cox, Tom and Amanda Griffiths. 2010. "Work-related stress: a theoretical perspective.” In: Leka, S. and Houndmont, J. (ed.) Occupational Health Psychology. Oxford, UK: Wiley Blackwell. 
Dalgard, Odd Steffen, Tom S $\oslash$ rensen, Inger Sandanger, Jan F. Nygård, Elisabeth Svensson, and Deborah L. Reas. 2009. "Job demands, job control, and mental health in an 11-year follow-up study: Normal and reversed relationships." Work \& stress 23 (3): 284-296.

Eisenhardt, Kathleen M. 1989. "Building theories from case study research." Academy of management review 14 (4): 532-550.

Edmondson Amy C. and Stacy E. Mc Manus 2007. "Methdological fit in management field research.” Academy of management review 32 (4): 1155-1179.

Forza, Cipriano. 1996. "Work organization in lean production and traditional plants: what are the differences?" International Journal of Operations \& Production Management 16 (2): 4262.

Fullerton, Rosemary R., Frances A. Kennedy, and Sally K. Widener. 2014. "Lean manufacturing and firm performance: The incremental contribution of lean management accounting practices." Journal of Operations Management 32 (7): 414-428.

García, Jorge, Denisse Rivera, and Alejandro Iniesta. 2013. "Critical success factors for Kaizen implementation in manufacturing industries in Mexico." International Journal of Advanced Manufacturing Technology 68.

Garcia-Sabater, Julio J., and Juan A. Marin-Garcia. 2011. "Can we still talk about continuous improvement? Rethinking enablers and inhibitors for successful implementation." International Journal of Technology Management 55(1/2): 28-42.

Gioia, Dennis A., Kevin G. Corley, and Aimee L. Hamilton. 2013. "Seeking qualitative rigor in inductive research: Notes on the Gioia methodology." Organizational Research Methods 16 (1): 15-31.

Golicic Susan L. and Donna F. Davis. 2012. "Implementing mixed methods research in supply chain management." International Journal of Physical Distribution \& Logistics Management, 42 (8/9): 726-741.

Goodyer, Jane, Nigel Grigg and Yashwant Murti. 2011. Sustaining lean manufacturing in New Zealand organisations, Technical Report, Massey University.

Greene, Jennifer C., Valerie J. Caracelli and Wendy F. Graham 1989. “Toward a conceptual framework for mixed-methods evaluation designs.” Educational Evaluation and Policy Analysis 11(3): 255-274. 
Hasle, Peter, Anders Bojesen, Jensen Per Langaa and Pia Bramming 2012. "Lean and the working environment: A review of the literature.” International Journal of Operations \& Production Management 32(7): 829-849.

Imai Masaaki. 1986. Kaizen: The Key to Japan’s Competitive Success. New York: Random House.

Jaca, Carmen, Elisabeth Viles, Luis Paipa-Galeano, Javier Santos, and Ricardo Mateo. 2014. "Learning 5S principles from Japanese best practitioners: case studies of five manufacturing companies." International Journal of Production Research 52 (15): 4574-4586.

Jackson, Paul R., and Robin Martin. 1996. "Impact of just-in-time on job content, employee attitudes and well-being: a longitudinal study." Ergonomics 39 (1): 1-16.

Jurburg, Daniel, Elisabeth Viles, Carmen Jaca, and Martin Tanco. 2015. "Why are companies still struggling to reach higher continuous improvement maturity levels? Empirical evidence from high performance companies”. TQM Journal, 27 (3): 316-327.

Karasek, Robert 1979. “Job demands, job decision latitude, and mental strain: implications for job design”, Administrative Science Quarterly, (24): 285-308.

Karasek, Robert, and Tores Theorell. 1992. Healthy work: stress, productivity, and the reconstruction of working life. New York: Basic books.

Knol, Wilfred H., Jannes Slomp, Roel L.J. Schouteten and Kristina Lauche 2018. “Implementing lean practices in manufacturing SMEs: testing 'critical success factors' using Necessary Condition Analysis”, International Journal of Production Research, published online 4 january 2018.

Koukoulaki, Theoni. 2014. "The impact of lean production on musculoskeletal and psychosocial risks: An examination of sociotechnical trends over 20 years." Applied Ergonomics 45 (2): 198-212.

Kristof-Brown, Amy L., Ryan D. Zimmerman, and Erin Johnson. 2005. "Consequences of individual's fit at work: A meta-analysis of person-job, person-organization, person-group, and person-supervisor fit.” Personnel Psychology 58: 281-342.

Kruger, Richard, and Mary A. Casey. 2000. Focus groups, Sage, Thousand Oaks, 3rd ed. Lawler, Edward E., and Susan A. Mohrman. 1987. "Quality circles: After the honeymoon." Organizational dynamics 15 (4): 42-54. 
Lewchuk, Wayne, and David Robertson. 1999. "The Canadian Automobile Workers and Lean Production: Results of a Worker-Based Benchmarking Study." Globalization and Patterns of Labour Resistance, London: Mansell.

Lewchuk, Wayne, Paul Stewart, and Charlotte Yates. 2001. "Quality of working life in the automobile industry: A Canada

Aldk Eochperdotyye tstadk."and Employment 16 (2): 72-87.

Liker, Jeffrey K. 2004. The toyota way. New York: McGraw Hill.

Longoni, Annachiara, Mark Pagell, David Johnston, and Anthony Veltri. 2013. "When does lean hurt?-an exploration of lean practices and worker health and safety outcomes." International Journal of Production Research 51(11): 3300-3320.

Monroe, Kimberly, Faye Fick, and Madina Joshi. 2012. "Successful integration of ergonomics into continuous improvement initiatives." Work 41 (1): 1622-1624.

Morse, Janice M. 1991. “Approaches to qualitative-quantitative methodological triangulation.” Nursing Research, 40: 120-123.

Netland, Torbjørn H. 2016. “Critical Success Factors for Implementing Lean Production: The Effect of Contingencies.” International Journal of Production Research 54 (8): 2433-2448.

Olivella, Jordi, Lluís Cuatrecasas, and Nestor Gavilan. 2008. "Work organisation practices for lean production." Journal of Manufacturing Technology Management 19 (7): 798-811.

Oropesa, Vento, Midiala, Garcia Alcaraz Jorge Luis, Maldonado Macias Aide Aracely, and Valeria Martinez Loya. 2016. "The impact of managerial commitment and Kaizen benefits on companies." Journal of Manufacturing Technology Management 27 (5): 692-712.

Panari, Chiara, Dina Guglielmi, Silvia Simbula, and Marco Depolo, 2010. "Can an opportunity to learn at work reduce stress? A revisitation of the job demand-control model.” Journal of Workplace Learning, 22(3): 166-179.

Pettersen, Jostein. 2009. "Defining lean production: Some conceptual and practical issues.” The TQM Journal 21(2): 127-142.

Saunders Mark N.K., Dietz Graham and Adrian Thornhill. 2014. "Trust and distrust: Polar opposites, or independent but co-existing?” Human Relations, 67(6): 639-665. 
Saurin, Tarcisio Abreu, and Cleber Fabricio Ferreira. 2009. "The impacts of lean production on working conditions: A case study of a harvester assembly line in Brazil." International Journal of Industrial Ergonomics 39 (2): 403-412.

Shah, Rachna, and Peter T. Ward. 2003. "Lean manufacturing: context, practice bundles, and performance." Journal of operations management 21 (2): 129-149.

Shoaf, Christin, Ash Genaidy, Waldemar Karwowski, and Samuel Huang. 2004. "Improving performance and quality of working life: A model for organizational health assessment in emerging enterprises." Human Factors and Ergonomics in Manufacturing \& Service Industries 14 (1): 81-95.

Strike, Vanessa M., and Claus Rerup. 2016. "Mediated sensemaking." Academy of Management Journal 59 (3): 880-905.

Tortorella, Guilherme Luz, Giuliano Almeida Marodin, Rogério Miorando and André Seidel. 2015. "The impact of contextual variables on learning organization in firms that are implementing lean: a study in Southern Brazil." The International Journal of Advanced Manufacturing Technology 78 (9-12): 1879-1892.

Vieira, Leandro, Giles Balbinotti, Adriano Varasquin, and Leila Gontijo. 2012. "Ergonomics and Kaizen as strategies for competitiveness: a theoretical and practical in an automotive industry.” Work, 41: 1756-1762.

Von Thiele Schwarz, Ulrica, Karina Nielsen, Terese Stenfors-Hayes and Henna Hasson (2017) “Using Kaizen to improve employee well-being: Results from two organizational intervention studies” Human Relations, 70 (8): 966-993.

Westgaard, Rolf H., and Jorgen Winkel. 2011. "Occupational musculoskeletal and mental health: Significance of rationalization and opportunities to create sustainable production systems-A systematic review." Applied ergonomics 42 (2): 261-296.

Womack, James P., and Daniel T. Jones. 2010. Lean thinking: banish waste and create wealth in your corporation. New York: Simon and Schuster.

Yin, Robert K. 2013. Case study research: Design and methods. London: Sage.

Zacharatos, Anthea., Barling Julian and Roderick D. Iverson. 2005. "High-performance work systems and occupational safety.” Journal of Applied Psychology, 90 (1): 77-93. 